\title{
棉花花器官突变体的鉴定及候选基因的克隆
}

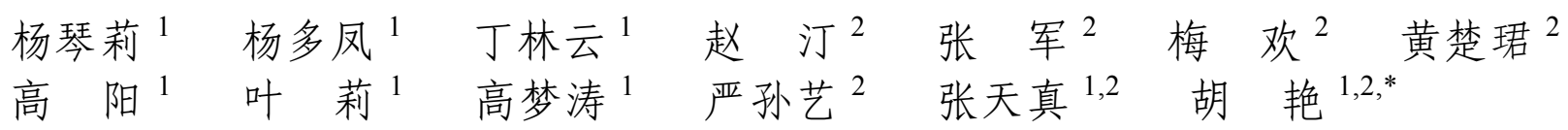

1 南京农业大学作物遗传与种质创新国家重点实验室, 江苏南京 $210095 ;{ }^{2}$ 浙江大学农业与生物技术学院, 浙江杭州 310058

摘 要: 棉花是世界性的重要经济作物, 是天然纤维的主要来源。棉花生殖生长过程现蕾、开花、结铃都直接影响 棉花主要经济性状一一棉纤维的产量和品质。本研究在转基因棉花材料中发现了 1 个花器官突变体, 命名为 $182-9$, 其花器官呈现瓣化特征。PCR 和 Southern 杂交证明突变体 182-9 中的外源基因已整合到基因组中，且为单拷贝插入。 通过基因组重测序进行序列比较发现, 突变体 182-9 基因组中外源 T-DNA 插入位点为染色体 A11:59086840。PCR 和 Southern 杂交对插入位点进行了进一步验证。根据棉花基因组注释结果, 在基因组插入位点附近有 3 个候选基因 (GH_A11G2251、GH_A11G2252 和 GH_A11G2253)。其中 GH_A11G2251 为 AP2 类基因。已有研究证明, $A P 2$ 类基因 为花器官 $\mathrm{ABC}$ 模型中控制募片和花瓣形成的 $\mathrm{A}$ 类功能基因。qRT-PCR 结果显示, GH_A11G2251 在转基因受体 W0 的花瓣、雌蕊和雄莈 3 个组织中的表达与突变体 182-9 中存在显著性差异。本研究为进一步深入探究棉花花器官发 育的分子机制研究提供了参考。

关键词：棉花; 转基因; 花器官; 突变体; 基因克隆

\section{Identification of a cotton flower organ mutant $182-9$ and cloning of candidate genes}

YANG Qin-Li ${ }^{1}$, YANG Duo-Feng ${ }^{1}$, DING Lin-Yun ${ }^{1}$, ZHANG Ting ${ }^{2}$, ZHANG Jun ${ }^{2}$, MEI Huan ${ }^{2}$, HUANG Chu-Jun ${ }^{2}$, GAO Yang ${ }^{1}$, YE Li ${ }^{1}$, GAO Meng-Tao ${ }^{1}$, YAN Sun-Yi ${ }^{2}$, ZHANG Tian-Zhen ${ }^{1,2}$, and HU Yan ${ }^{1,2, *}$

${ }^{1}$ State Key Laboratory of Crop Genetics and Germplasm Enhancement, Nanjing Agricultural University, Nanjing 210095, Jiangsu, China; ${ }^{2}$ College of Agricultural \& Biotechnology, Zhejiang University, Hangzhou 310000, Zhejiang, China

\begin{abstract}
Cotton is an important economic crop and the main source of natural fiber in the world. The budding, flowering and bolling during cotton growth and development directly affect the yield and quality of cotton fiber that are the main economic traits of cotton. In this study, we found a flower organ mutant (named 182-9) in transgenic cottons, which displayed the floral organ petaloid feature. PCR and Southern blotting confirmed that the foreign T-DNA was integrated into the $182-9$ genome with a single copy. Comparative analysis of the resequencing data revealed that the exogenic T-DNA was inserted in the 182-9 on chromosome A11: 59086840. The insertion site was further verified by PCR and southern blot. According to the gene annotation of cotton genome, there were three candidate genes of $G H_{-} A 11 G 2251, G H_{-} A 11 G 2252$, and $G_{-} A 11 G 2253$, near to the insertion site. $G H$ $A 11 G 2251$ encoded AP2 genes controlling the formation of sepals and petals in the ABC model of flower organs as previous report. qRT-PCR showed that there were significant differences in the expression level of $G H \_A 11 G 2251$ in petals, pistil and stamens of transgenic receptor W0 and mutant 182-9. Our study provided the basis for further study of molecular mechanism in cotton floral organ development.
\end{abstract}

Keywords: cotton; transgenic; floral organ; mutant; gene cloning

本研究由国家自然科学基金项目(31970320)和国家转基因生物新品种培育重大专项(2016ZX08009-003)资助。

This study was supported by the National Natural Science Foundation of China (31970320) and the National Major Project for Developing New GM Crops (2016ZX08009-003).

*通信作者(Corresponding author): 胡艳, E-mail: njauhuyan@njau.edu.cn

第一作者联系方式: E-mail: 739768392@qq.com

Received (收稿日期): 2020-09-10; Accepted (接受日期): 2021-01-13; Published online (网络出版日期): 2021-03-11.

URL: https://kns.cnki.net/kcms/detail/11.1809.S.20210310.1713.002.html 
棉花是世界上重要的经济作物和油料作物, 在 世界上超过 100 个国家和地区种植。棉花纤维是纺 织工业天然纤维的重要来源 ${ }^{[1]}$ 。纤维由棉花胚珠表 皮细胞突起形成 ${ }^{[2]}$, 因此棉花花器官的分化和发育 直接影响棉花的产量和纤维品质。在植株的生长发 育过程中, 植物顶端分生组织由发育成叶原基转变 为开始发育成花原基 ${ }^{[3]}$, 是营养生长到生殖生长的 转变。花器官的分化和发育是被子植物生命周期的 重要阶段 ${ }^{[4]}$ 。典型的花器官分为 4 个部分, 从外到内 依次是萼片、花瓣、雄蕊、心皮, 它们组成了花发 育的 4 个轮回 ${ }^{[5-6]}$ 。

1991 年, Coen 和 Meyerowitz ${ }^{[7]}$ 首次系统地解释 了花发育相关基因(主要是 MADS 盒基因)在不同花 器官发育中的作用。已知 MIKC 型的 MADS-box 基 因是植物特有的, 它们在开花植物 (被子植物)生殖 发育中的作用尤为重要 ${ }^{[8]}$ 。绝大多数 MIKC 型基因 属于花器官决定基因, 它建立了被子植物花发育的 基本框架，保障了“ $\mathrm{AE}$ 模型” ${ }^{[9]}$ 的保守性，并参与 调控开花时间、花器官和花分生组织识别、果实发 育、营养器官发育 ${ }^{[10-11]}$ 等过程。除了 MADS-box 基 因家族外，还有一类 APETALA2 (AP2)基因在花发育 过程中扮演了重要角色。AP2 基因属于花发育模型 中 $\mathrm{A}$ 类基因。最早发现拟南芥胚珠和雌配子体发育 所需的 AINTEGUMENTA 基因与花型同源异形基因 $A P 2$ 有关。编码的蛋白质 AINTEGUMENTA (ANT)属 于 $A P 2$ 相关基因家族, 是胚珠发育所必需的 ${ }^{[12-13]}$ 。 已有研究表明, 拟南芥中 $A N T$ 基因在其子房及雌配 子体发育过程中发挥了关键作用 ${ }^{[13-16]}$ 。同时为了更 好地理解 $A N T$ 基因在控制胚珠发育中的作用, 研究 人员从拟南芥中分离出 1 个 $A N T$ 雌性不育突变体。 在该突变体的胚珠中, 胚珠不发育。当 $A N T$ 突变体 与花同源突变体 $A P 2$ 结合时, 花器官结构就会完全 丧失，表明这 2 个基因共同启动了花发育 ${ }^{[12]}$ 。

有关棉花花器官发育相关基因已有报道。Wang 等 ${ }^{[17]}$ 从陆地棉中分别克隆到了 1 个 SQUAMOSA 类 似基因和 1 个开花启动因子 GhFPF1 基因, 并在转 基因拟南芥中进行了功能验证。Zhang 等 ${ }^{[18-19]}$ 对 $G h L F Y$ 和 GhSPL 基因家族进行了鉴定和分析，证实 $G h S O C 1$ 与 $G h S P L 3$ 和 $G h L F Y$ 基因启动子结合以调 节开花。而后研究确定了 GhSOC1 和 GhMADS42 的 功能及其调控机制, 为早期成熟棉花品种发展提供 了有用的信息 ${ }^{[19]}$ 。研究表明 GhMADS12 基因属于 $\mathrm{PI}$ 亚家族，为 $\mathrm{B}$ 类功能基因，基因 GhMADS13 属于
$A G L 6$ 亚家族, 行使 $\mathrm{C}$ 类基因功能 ${ }^{[20]}$ 。烟草植物中导 入 GhMADS12 和 GhMADS13 基因, 证实了基因在相 应花器官发育中的作用 ${ }^{[20]}$ 。此外, $A P 2$ 基因在植物的 花发育网络调控中也扮演了重要角色。了解 $A P 2$ 基 因与其他基因的相互作用关系，有利于我们更好地 理解花发育调控的基本框架 ${ }^{[21]}$ 。已知 $A P 1$ 与 $A P 2$ 同 属于 $\mathrm{A}$ 类功能基因, 它们共同调控花营和花瓣的发育, 且 2 个基因被证明有一定的叠加效应, 它们共同影响了 花原基的建成 ${ }^{[16]}$ 。在花的发育过程中, $A G$ 基因与 $A P 2$ 基因作用最为明显。已有研究表明, 在 $a g$ 突变体中, 很 多 $A G$ 负调控因子中 $A P 2$ 的作用最强, $A G$ 将 $A P 2$ 的表 达限制在花器官形成的第 $1 、 2$ 轮回中 ${ }^{[22-23]}$ 。miR172 对 $A P 2$ 的表达也有一定的调控作用。由于 $A P 2$ 结构中存 在 1 个 miR172 的结合位点, 因此二者结合之后, $\operatorname{miR} 172$ 在翻译水平抑制了 $A P 2$ 蛋白质的形成 ${ }^{[21]}$ 。总之, 在各类基因相互作用下形成的复杂调控网络, 共同调 节了植物的花发育进程。

本研究在转基因棉花中发现了 1 个花器官突变 体 182-9。突变体表现为花器官异常, 莒片相对细长 偏大, 花瓣和雄芯结构异常。Southern 杂交表明, T-DNA 在基因组中为单拷贝插入。利用基因组重测 序数据进行比较基因组分析, 鉴定出 T-DNA 在突变 体 182-9 基因组的插入位点进行了准确定位。插入 位点附近存在 3 个候选基因，其中包括 1 个 $A P 2$ 类 基因, 在突变花器官中表达量显著低于正常花器 官。推测可能由于 T-DNA 的插入导致 1 个 $A P 2$ 类基 因的表达发生差异变化, 从而引起花器官突变表型。

\section{1 材料与方法}

\section{1 试验材料}

花器官突变体 182-9 为转基因植株。植物材料 种植于浙江大学农生环 9 号温室(培养条件: 温度 22 ${ }^{\circ} \mathrm{C}$, 光照 $16 \mathrm{~h} /$ 黑暗 $8 \mathrm{~h}$, 相对湿度 75\% 80\%)。试验 中转基因载体为 GoPGF-RNAi，载体骨架序列为 pBI121 载体(图 1)保存于本实验室。

\subsection{DNA、RNA 提取及 cDNA 合成}

采用 $\mathrm{CTAB}$ 法提取转基因受体 $\mathrm{W} 0$ 和花器官突变体 182-9 新鲜叶片 DNA。按照 EASY spin Plus 植物 RNA 快速提取试剂盒(Adlab, 北京)指示说明书, 分别提取 $\mathrm{W} 0$ 和 182-9 的颌片、花瓣、雄蕊和雌蕊 4 个组织的 RNA。 植物材料于液氮中速冻后保存于 $-80^{\circ} \mathrm{C}$ 超低温冰箱中备 用。使用反转录试剂盒将各组织 RNA 反转成 $\mathrm{cDNA}$ 。 


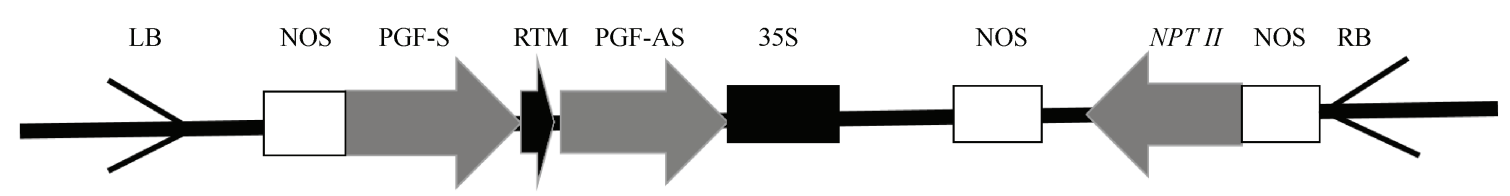

图 1 转基因载体 T-DNA 序列

Fig. 1 T-DNA structure of the transgenic vector

\subsection{Southern 印记杂交}

提取叶片 DNA 后, 取 $20 \mu \mathrm{g}$ 基因组 DNA，加入 $150 \mathrm{U}$ 的 Hind III 内切酶和 $20 \mu \mathrm{L}$ 限制性内切酶缓冲 液, 加无菌重蒸水至总体积 $200 \mu \mathrm{L}, 37^{\circ} \mathrm{C}$ 保温过夜。 Hind III 内切酶(南京诺唯赞生物科技股份有限公司, 简称诺唯赞)酶切后的质粒作为阳性对照。以 NPTII 基因扩增产物(约 $196 \mathrm{bp}$ )和 T-DNA 扩增产物做探针, 分别检测外源基因插入的拷贝数以及插入位点的验 证。NPTII 基因扩增引物序列为 F: 5'-ACCTGTCCGGT GCCCTGAATGAACTGC-3'和 R: 5'-GCCATGATGGAT ACTTTCTCGGCAGGAGC-3'; T-DNA 插入片段扩增引 物序列为 F: 5'-TGGGTGATGGTTCACGTAGT-3'和 R: 5'-CATAATCATGTTAAAATGCTTGG-3'。将酶切后的 基因组 DNA 在 $0.8 \%$ 琼脂糖凝胶中电泳过夜。通过 纸吸印法转移到尼龙膜上, 参照 DIG High Prime DNA Labeling and Detection Starter Kit I (Roche)试 剂盒进行探针标记、预杂交、杂交及检测。

\subsection{T-DNA 插入位点鉴定}

为明确外源 T-DNA 插入基因组的准确位点, 本研 究对花器官突变体 182-9 和受体 W0 进行高深度的 Illumina PE150 基因组重测序。对所获得数据进行过滤 去除低质量 reads。利用 Blastn ${ }^{[24]}$ 软件将高质量 reads 比 对 $\mathrm{pBI} 121$ 载体序列。提取比对到 pBI121 载体序列的另 一端数据, 使用软件 hisat $2^{[25]}$ 比对陆地棉 $\mathrm{TM}-1$ 参考基 因组(V2.1) (cotton.zju.edu.cn), 估算插入位点。

\section{5 候选基因的克隆}

从本实验室 TM-1 基因组(V2.1)数据库中获取候 选基因 $G H \_A 11 G 2251 、 G H \_A 11 G 2252$ 和 $G H_{-} A 11$ $G 2253$ 三个基因的 CDS 序列, 设计引物对 3 个基因 进行克隆, 引物序列分别为 $G H \_A 11 G 2251\left(\mathrm{~F}: 5^{\prime}-\right.$ ATGAAGTCCATGAGCAATGATG-3'，R: 5'-CTAAG CATCTGTCCAGGCAGT-3')、GH_A11G2252 (F: 5'ATGCAAAAGGAGGCTGCTCTTTT-3', R: 5'-CTATA GCTTACACATGAGC-3')、GH_A11G2253 (F: 5'-ATG GAAGGAAGTATACCCTT-3'，R: 5'-CTAGACAAAT TCATGTAAACCACG-3')。

\section{6 实时苂光定量 PCR (RT-PCR)}

以棉花 Histone 3 基因(Acc. No. AF024716, F: 5'-
GGTGGTGTGAAGAAGCCTCAT-3'，R: 5'-AATTTC ACGAACAAGCCTCTGGAA-3') 为内参对表达数据 进行标准化。使用诺唯赞 SYBR Green I kit 染料, 在 苂光定量 RT-PCR 仪(ABI 7500)上进行分析, 以最小 的样本阈值循环数 ( $\mathrm{Ct}$ 值) 和最高的苂光值为标准。 反应体系与程序按照诺唯赞 AceQ qPCR SYBR Green Master Mix 试剂盒说明书进行。引物序列分别 为: $G H \_A 11 G 2251$-QF: 5'-ATGGAGGTTAGCAATC AAGG-3', GH_A11G2251-QR: 5'-AGATGAGATGGT GGAGATGG-3'; GH_A11G2252-QF: 5'-GTTTAGAC GAGTGGAAGCC-3', GH_A11G2252-QR: 5'-AGTTT GGAGTGTCCTAATGC-3'; GH_A11G2253-QF: 5'-G GCCTATAAAGCGTGTACC-3'; GH A11G2253-QR: 5'-TAATTCGGAGCTACAAGTGC-3'。采用 $2^{-\Delta \Delta C t}$ 法 计算相对表达量, 计算公式如下: 目的基因的相对

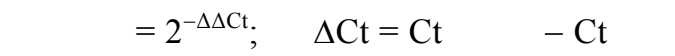

\section{2 结果与分析}

\section{1 花器官突变体 182-9 表型鉴定}

本研究以棉花野生型 W0 为受体, 在转基因材 料中发现 1 个转基因克隆株系表现为花器官突变体, 命名为 182-9。突变体花器官呈现明显的生理缺陷构 造, 整个花器官显著变小, 外围苞叶相对卷曲窄小, 莒片相对细长偏大, 花瓣和雄芯结构异常, 失去了 花器官四轮结构, 均呈现类似细长叶片状态, 心皮 中无胚珠(图 2)。

\section{2 突变体 182-9 的分子检测}

对转基因突变体 182-9 进行 NPT II 基因 PCR 检 测发现, 182-9 为转基因阳性克隆, 外源 T-DNA 片段 已经整合到基因组中(图 3)。

\section{3 突变体 182-9 的 Southern 检测}

为进一步确定 T-DNA 在突变体 182-9 中的插入 拷贝数, 本研究根据外源基因 NPT II 设计探针, 与 转基因获得的不同克隆的基因组 DNA（包括突变体 182-9)进行 Southern 杂交。同时, 以质粒 DNA 为阳 性对照, 野生型 W0 为阴性对照。结果显示, 突变体 182-9 中 T-DNA 已稳定整合到基因组中且为单拷贝 插入(图 4)。 
A

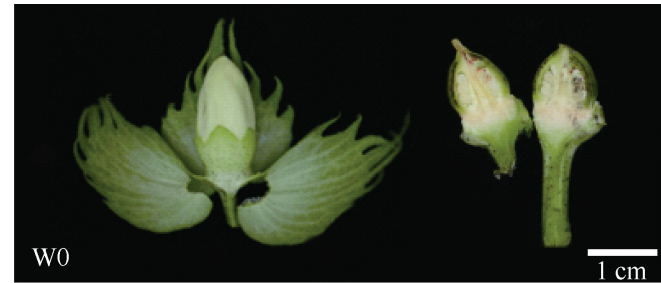

B

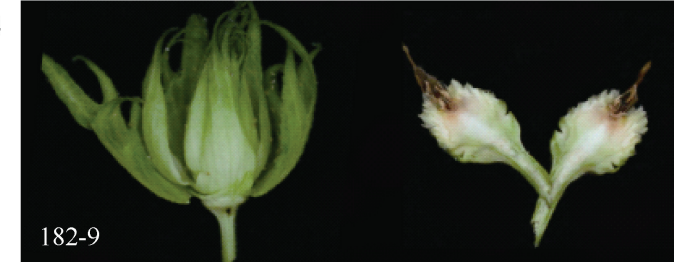

$\mathrm{C}$

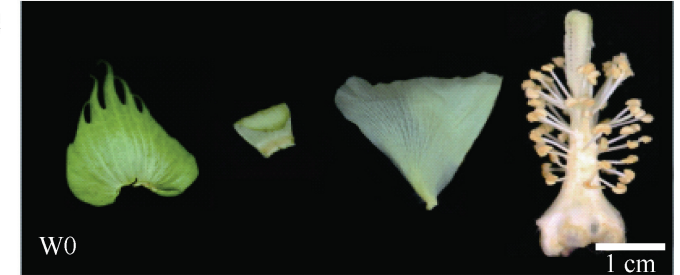

D

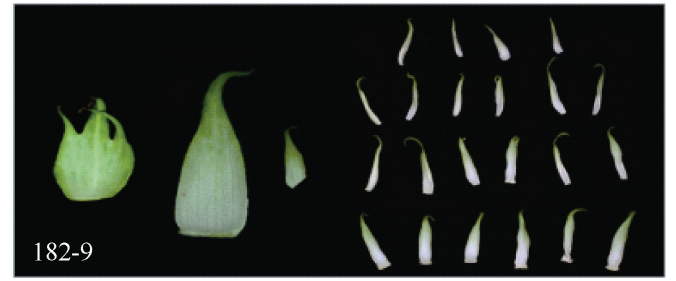

图 2 突变体 182-9 与转基因受体 W0 花器官表型比较

Fig. 2 Phenotype comparison of floral organ between the mutant $182-9$ and transgenic receptor $\mathrm{W}_{0}$

A：转基因受体 W0 花器官整体结构与子房。B: 突变体 $182-9$ 花 器官结构。C: 转基因受体 W0 苞叶、蕺片、花瓣、雌莎雄莎结 构。D: 突变体 182-9 苍叶、募片以及瓣化结构。标尺为 $1 \mathrm{~cm}$ 。 A: the whole flower organ and ovary of transgenic receptor W0. B: floral organ of the mutant 182-9. C: bract, sepal, petal, pistil stamen of transgenic receptor W0. D: bracts, sepals, and petaloid structure of the mutant 182-9. Bar: $1 \mathrm{~cm}$.

\section{4 插入位点在参考基因组中的定位}

我们对转基因受体 $\mathrm{W} 0$ 和突变体 $182-9$ 进行基 因组重测序, 分别产生了 $70.8 \mathrm{~Gb}$ 和 $73.7 \mathrm{~Gb}$ 的数据, 覆盖基因组约 30 倍(以棉花基因组 $2.5 \mathrm{~Gb}$ 计算) (表 1)。其中, Sample 代表样品名, Raw Base (bp)表示原 始数据产量, Clean Base 是过滤之后的有效数据量, 即过滤后测序序列的个数乘以测序序列的长度, Q30 即 Phred 数值大于 30 的碱基占总体碱基的百分比。
为鉴定 T-DNA 在受体 W0 基因组中的插入位点, 本 研究将重测序 reads 分别比对到载体 $\mathrm{pBI} 121$, 在转 基因材料 182-9 和转基因受体 $\mathrm{W} 0$ 重测序 reads 中, 分别有 41 条和 0 条序列和载体具有同源性。使用软 件 hisat $2{ }^{[25]}$ 将 41 条 reads 的另一端再比对到 TM-1 的参考基因组上发现, 共有 15 条 reads 能唯一匹配 到陆地棉 TM-1 A11 染色体的 59,086,746 59,086,947 的区间，推测位点为外源 T-DNA 的插入位点。

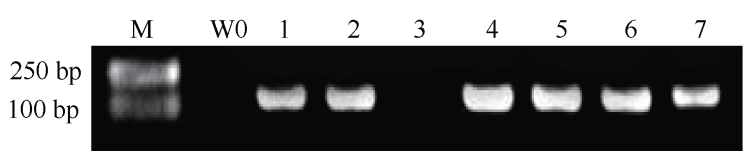

图 3 PCR 检测转基因材料(182-9) NPTII 基因

Fig. 3 PCR detection of NPTII gene in transgenic mutant 182-9 M: DNA 分子量 Marker; W0: 阴性对照; 1 : 转基因株系 182-9; 2: 转基因株系 182-36；3：转基因株系 182-91；4：转基因株系 182-150； 5: 转基因株系 182-172；6: 转基因株系 182-173； 7：转 基因株系 182-187。

M: DNA molecular-weight markers; W0: negative control; 1: transgenic line 182-9; 2 : transgenic line 182-36; 3: transgenic line 182-91; 4: transgenic line 182-150; 5: transgenic line 182-172; 6 : transgenic line 182-173; 7: transgenic line 182-187.

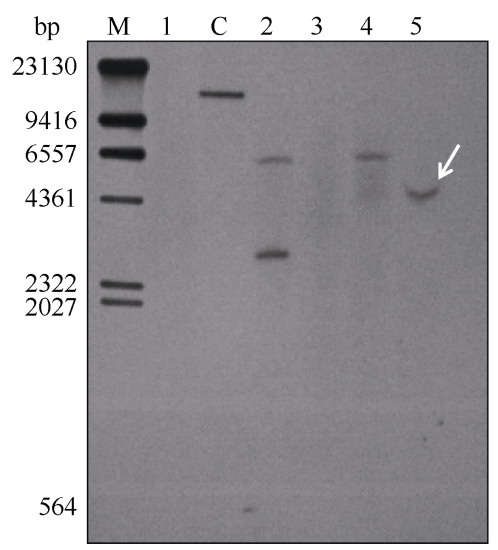

图 4 Southern 杂交检测突变体 182-9 中外源基因 NPTII 的整合 Fig. 4 Southern blotting of NPTII gene in mutant 182-9 genome M：DNA marker； 1: 转基因受体 W0；C：质粒；2：转基因株系 182-187; 3: 转基因株系 182-36; 4: 转基因株系 182-173; 5: 转基 因株系 182-9 (箭头所示)。

M: DNA marker; 1: transgenic receptor W0; C: plasmid; 2: transgenic line 182-187; 3: transgenic line 182-36; 4: transgenic line 182-173; 5: transgenic line 182-9 (indicated by the arrow).

表 1 重测序数据评估

Table 1 Evaluation of the resequencing data

\begin{tabular}{ccccccc}
\hline $\begin{array}{c}\text { 样品 } \\
\text { Sample }\end{array}$ & $\begin{array}{c}\text { 原始 reads } \\
\text { Raw reads }\end{array}$ & $\begin{array}{c}\text { 过滤后 reads } \\
\text { Clean reads }\end{array}$ & $\begin{array}{c}\text { 原始碱基数 } \\
\text { Raw base }(\mathrm{Gb})\end{array}$ & $\begin{array}{c}\text { 过滤后碱基数 } \\
\text { Clean base }(\mathrm{Gb})\end{array}$ & $\begin{array}{c}\text { Q30 } \\
(\%)\end{array}$ & $\begin{array}{c}\text { GC 含量 } \\
\text { GC content }(\%)\end{array}$ \\
\hline $182-9$ & $245,670,776$ & $245,536,479$ & 73.70 & 73.66 & 91.81 & 35.43 \\
W0 & $236,081,132$ & $235,926,310$ & 70.82 & 70.78 & 89.16 & 35.51 \\
\hline
\end{tabular}


为进一步验证外源 T-DNA 的插入位点。根据重 测序分析结果, 本研究利用 SeqHunter1.0 提取陆地 棉 TM-1 基因组中该位点上下游 $2 \mathrm{~kb}$ 序列, 设计特 异性引物, 分别以突变体 182-9 和野生型 W0 的基因 组 DNA 为模板，扩增序列并测序。PCR 扩增结果显
示, 突变体 182-9 能扩增出约 $400 \mathrm{bp}$ 的特异性序列 (图 5-A)。测序结果证明, 突变体 182-9 基因组中 T-DNA 插入位点在染色体 A11 上的 59,086,840 位置, 红色部分为该位点附近的棉花基因组序列, 前半部 分为载体序列(图 5-B)。

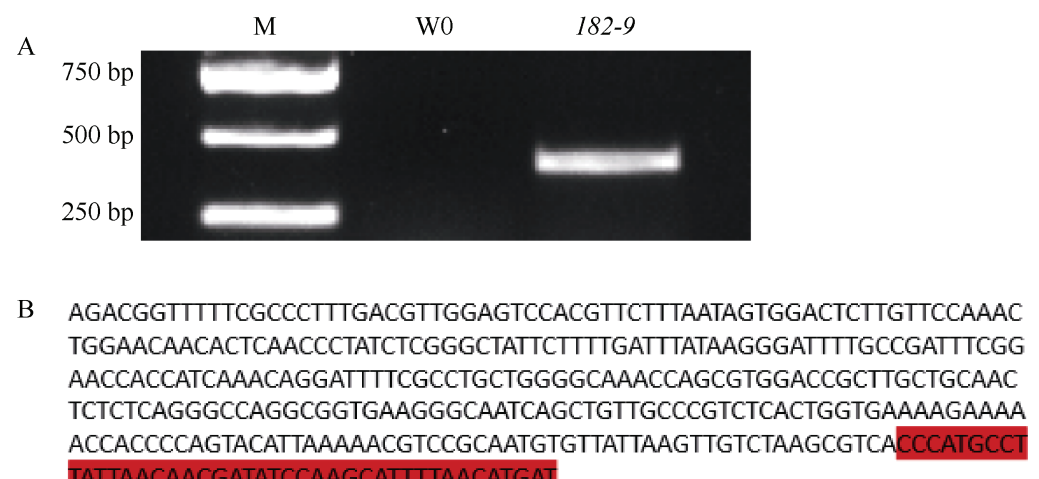

图 5 PCR 检测外源 T-DNA 在基因组中插入位点

Fig. 5 PCR detection of the T-DNA insertion site in mutant 182-9

A： PCR 扩增条带; B：扩增序列的测序结果(红色部分为棉花基因组序列，其他为 T-DNA 序列)。 M：DNA marker; W0：转基因受体; 182-9: 转基因株系。

A: diagram of PCR detection; B: the sequencing results of the amplified sequence from 182-9 (the red part is the cotton genome sequence, and the others are T-DNA sequences). M: DNA marker; W0: transgenic receptor; 182-9: transgenic line.

根据 PCR 验证结果，本研究以图 5-B 中的序列 为探针，与转基因突变体 182-9 基因组 DNA 进行 Southern 杂交。同时, 以探针序列为阳性对照, 转基 因株系 W0 为阴性对照。结果进一步验证了 182-9 基因组中外源 T-DNA 以单拷贝插入染色体 A11 上的 $59,086,840$ 位点(图 6)。

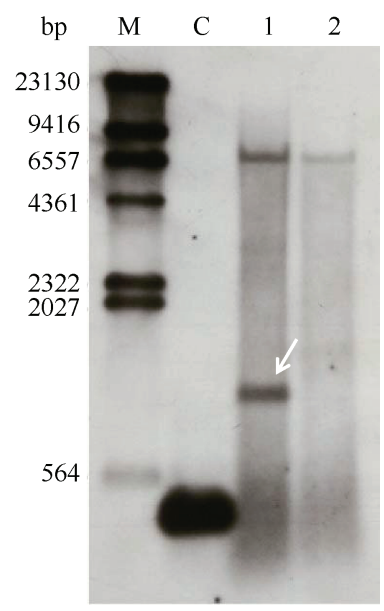

图 6 插入位点的 Southern 检测

Fig. 6 Southern blot detection of T-DNA insertion site M: DNA marker; C: 阳性质粒; 1：转基因株系 182-9；2：转基因 受体 W0。箭头所示为转基因 182-9 中特异性条带。

M: DNA marker; C: positive plasmid; 1: transgenic line 182-9; 2: transgenic receptor W0. The specific band of $182-9$ is shown by an arrow.

\section{5 候选基因的篮选和功能预测}

根据外源 T-DNA 插入基因组中的定位结果, 本研 究将外源插入 T-DNA 序列比对到陆地棉 TM-1 基因组, 根据陆地棉 TM-1 参考基因组注释结果(表 2), 在插入 位点 $400 \mathrm{~kb}$ 范围内存在 $G H \_A 11 G 2251 、 G H \_A 11 G 2252$ 和 $G H \_A 11 G 2253$ 三个功能基因(图 7)。根据拟南芥中 同源基因的功能注释发现, GH_A11G2251 为 $A P 2$ 类基 因, 已有文献报道 $A P 2$ 类基因在花器官分化中起着重 要作用, 为开花模型中 $\mathrm{A}$ 类基因。

为验证是否因为候选基因本身序列的突变而产 生突变表型, 本研究对 3 个候选基因在转基因受体 $\mathrm{W} 0$ 和花器官突变体 182-9中的基因序列进行了比较 发现, 3 个候选基因 CDS 序列在 182-9 和 W0 之间并 无差异(图 8 图 10), 表明 T-DNA 插入并未造成 3 个 候选基因的碱基序列差异。

选取 W0 和 182-9 典型花器官结构进行定量分 析。q-PCR 分析结果显示, GH $A 11 G 2251$ 在突变体 182-9 与转基因受体 W0 相应的花瓣 $(\mathrm{O} 2)$ 、雄蕊 $(\mathrm{O} 3)$ 和雌芯 $(\mathrm{O} 4)$ 中表现显著性差异, 在花瓣 $(\mathrm{O} 2)$ 和雌惢 (O4)突变体表达量显著低于转基因受体。GH_A11 G2252 在 2 个材料中表达无显著差异, GH_A11 $G 2253$ 在转基因受体 W0 花器官和突变体 182-9中几 乎不表达(图 11)。 


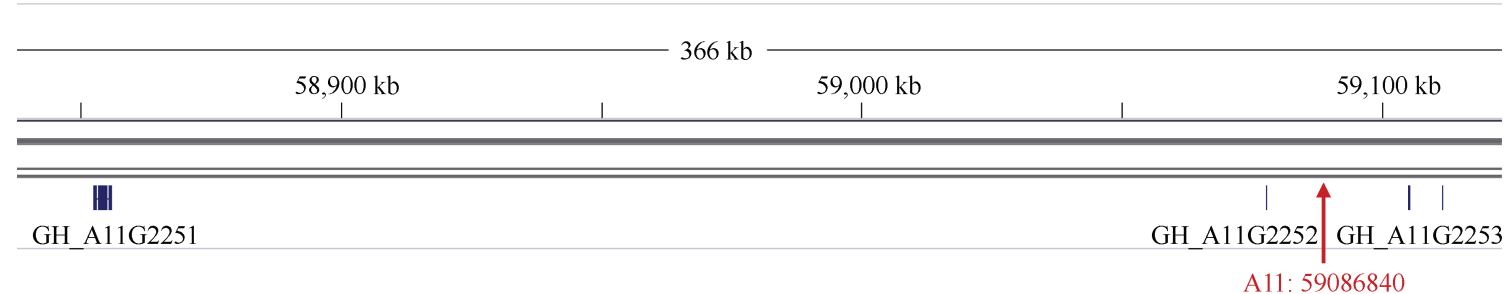

图 7 候选基因与插入位点的相对位置

Fig. 7 Position of the candidate gene relative to the insertion site

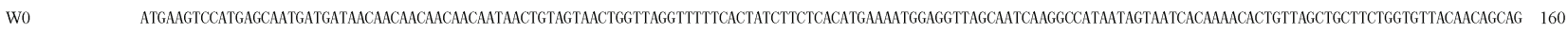
182-9 ATGAAGTCCATGAGCAATGATGATAACAACAACAACAACAATAACTGTAGTAACTGGTTAGGTTTTTCACTATCTTCTCACATGAAAATGGAGGTTAGCAATCAAGGCCATAATAGTAATCACAAAACACTGTTAGCTGCTTCTGGTGTTACAACAGCAG 160 GH_A11G2251 ATGAAGTCCATGAGCAATGATGATAACAACAACAACAACAATAACTGTAGTAACTGGTTAGGTTTTTCACTATCTTCTCACATGAAAATGGAGGTTAGCAATCAAGGCCATAATAGTAATCACAAAACACTGTTAGCTGCTTCTGGTGTTACAACAGCAG 160

Wo TTCCATCAAGCTTTTTCCCATCTCCACCATCTCATCTTAGTTATGGACTTTATTATGAAGGAGAAAATGGGGGCTTGTATTCTCACTTTCCTGTGATGCCACTAAAGTCTGATGGTTCTCTTTGTTTAATGGAAGCTCTTGGCAGGTCCCAGTCACAAGC 320 182-9 TTCCATCAAGCTTTTTCOCATCTCCACCATCTCATCTTAGTTATGGACTTTATTATGAAGGAGAAAATGGGGGCTTGTATTCTCACTTTCCTGTGATGCCACTAAAGTCTGATGGTTCTCTTTGTTTAATGGAAGCTCTTGGCAGGTCCCAGTCACAAGC 320 GH_A11G2251 TTCCATCAAGCTTTTTCCCATCTCCACCATCTCATCTTAGTTATGGACTTTATTATGAAGGAGAAAATGGGGGCTTGTATTCTCACTTTCCTGTGATGCCACTAAAGTCTGATGGTTCTCTTTGTTTAATGGAAGCTCTTGGCAGGTCCCAGTCACAAGC 320

W0

$182-9$

GH_A11G2251

wo

182-9

GH A11G225

W0

182-9

GH_A11G225

wo

182-9

GH A1lG225

W0

182-9

GH_A11G225

W0

182-9

GH A11G2251

wo

182-9

GH_A11G225

W0

182-9

GH A11G225

wo

182-9

GH_A11G225

W0

182-9

GH_A11G225

Wo

182-9

GH_A11G225

48OCOACTCACTCCTAAACTGGAGGATTTCTTTGGGGGTGCAACCATGGGGACCCATCACTATGAAAGCAGTGACAGAGAAACTATGGCTCTTAGCTTAGACAGCATGTATTACCATCAAAATCCCAATCAAGATCACAACTCTCAGAACTGC AATGGTTCCTACTTCAACTCCTAAACTGGAGGATTTCTTTGGGGGTGCAACCATGGGGACCCATCACTATGAAAGCAGTGACAGAGAAACTATGGCTCTTAGCTTAGACAGCATGTATTACCATCAAAATCCCAATCAAGATCACAACTCTCAGAACTGC 480 AATGGTTCCTACTTCAACTCCTAAACTGGAGGATTTCTTTGGGGGTGCAACCATGGGGACCCATCACTATGAAAGCAGTGACAGAGAAACTATGGCTCTTAGCTTAGACAGCATGTATTACCATCAAAATCCCAATCAAGATCACAACTCTCAGAACTGC 480

CTAGACCACCTGCAACACTCCTCGAGGCAGCAGCACCACCAACACCAACTTCAGGTCCAACAATACCAATACTACTCAGGATACAGAAACCAAGAAATGTTGCTAGCAGAAGAAGCTGATCAAGAAACCCATGTTACTGATTGCAATCTTCAGCTCCCAA 640 CTAGACCACCTGCAACACTCCTCGAGGCAGCAGCACCACCAACACCAACTTCAGGTCCAACAATACCAATACTACTCAGGATACAGAAACCAAGAAATGTTGCTAGCAGAAGAAGCTGATCAAGAAACCCATGTTACTGATTGCAATCTTCAGCTCCCAA 640 CTAGACCACCTGCAACACTCCTCGAGGCAGCAGCACCACCAACAOCAACTTCAGGTCCAACAATACCAATACTACTCAGGATACAGAAACCAAGAAATGTTGCTAGCAGAAGAAGCTGATCAAGAAACCCATGTTACTGATTGCAATCTTCAGCTCCCAA 640

CAATGGCAGATGATGGAAGCGCTGCTATGAAGCACTGGGCTTCAAGAAACTACTCCACTGAGCATTCTGCGATGAATCAGAAGATGATAGGgTGCATGGgTGATAATGGAGCTGACTCTGGCTCTATTGGTGCCATGGCATATGGAGATTTACAGTCTTT 800 CAATGGCAGATGATGGAAGCGCTGCTATGAAGCACTGGGCTTCAAGAAACTACTCCACTGAGCATTCTGCGATGAATCAGAAGATGATAGGGTGCATGGGTGATAATGGAGCTGACTCTGGCTCTATTGGTGCCATGGCATATGGAGATTTACAGTCTTT 800 CAATGGCAGATGATGGAAGCGCTGCTATGAAGCACTGGGCTTCAAGAAACTACTCCACTGAGCATTCTGCGATGAATCAGAAGATGATAGGgTGCATGGgTGATAATGGAGCTGACTCTGGCTCTATTGGTGCCATGGCATATGGAGATTTACAGTCTTT 800

GAGCTTGTCCATGAGCCCTGGCTCACAATCAAGCAGTGTTGCTGGTTCACAGCAAATCTCACCTTCTGCAACTGACTATGCAGCAATGGAAACCAAGAAAAGAGGGCCTGAGAAAGTAGATCAGAAGCAAATTGOCCACAGGAAATOCATTGATACTTTC 960 GAGCTTGTCCATGAGCCCTGGCTCACAATCAAGCAGTGTTGCTGGTTCACAGCAAATCTCACCTTCTGCAACTGACTATGCAGCAATGGAAACCAAGAAAAGAGGGOCTGAGAAAGTAGATCAGAAGCAAATTGCCCACAGGAAATOCATTGATACTTTC 960 GAGCTTGTCCATGAGCCCTGGCTCACAATCAAGCAGTGTTGCTGGTTCACAGCAAATCTCACCTTCTGCAACTGACTATGCAGCAATGGAAACCAAGAAAAGAGGGCCTGAGAAAGTAGATCAGAAGCAAATTGOCCACAGGAAATOCATTGATACTTTC 960

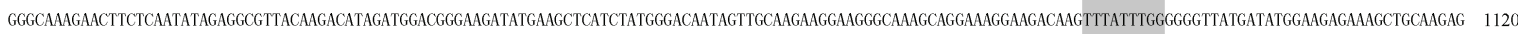
GGGCAAAGAACTTCTCAATATAGAGGCGTTACAAGACATAGATGGAGGGGAAGATATGAAGCTCATCTATGGGACAATAGTTGCAAGAAGGAAGGGCAAAGCAGGAAAGGAAGACAAGTTTATTTGGGGGGTTATGATATGGAAGAGAAAGCTGCAAGAG 1120

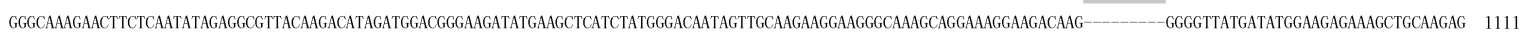

CTTATGATTTAGCTGCACTCAAGTATTGGGGACCCTCCACTCACATCAACTTCCCATTGGAAAATTACCAAAAAGAACTTGAGGAAATGAAGAACATGACTAGACAGGAGTATGTTGCTCATTTGAGAAGGAAAAGCAGTGGATTCTCAAGGGGAGCTTC 1280 CTTATGATTTAGCTGCACTCAAGTATTGGGGACCCTCCACTCACATCAACTTCCCATTGGAAAATTACCAAAAAGAACTTGAGGAAATGAAGAACATGACTAGACAGGAGTATGTTGCTCATTTGAGAAGGAAAAGCAGTGGATTCTCAAGGGGAGCTTC 1280 CTTATGATTTAGCTGCACTCAAGTATTGGGGACCCTCCACTCACATCAACTTCCCATTGGAAAATTACCAAAAAGAACTTGAGGAAATGAAGAACATGACTAGACAGGAGTATGTTGCTCATTTGAGAAGGAAAAGCAGTGGATTCTCAAGGGGAGCTTC 1271

AATGTACAGAGGAGTGACAAGACATCATCAGCATGGAAGATGGCAAGCTCGGATAGGCAGAGTTGCTGGGAACAAGGACCTTTATCTTGGAACATTTAGCACTCAGGAAGAAGCAGCCGAGGCTTATGACATAGOGGCTATCAAATTCCGTGGTGCGAAT 1440 AATGTACAGAGGAGTGACAAGACATCATCAGCATGGAAGATGGCAAGCTCGGATAGGCAGAGTTGCTGGGAACAAGGACCTTTATCTTGGAACATTTAGCACTCAGGAAGAAGCAGCCGAGGCTTATGACATAGCGGCTATCAAATTCCGTGGTGCGAAT 1440

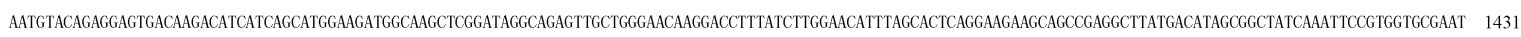

GCCGTGACAAATTTCGACATAACGAGGTACGATGTGGAACGAATCATGGCAAGCAGCACCCTCCTTGCTGGAGACCTGGCACGGCGAAACAAAGACATAGGACCTGCAAATGAGACTATCAACCACAATCTTTTAGTTCATAATAGCTACGGTGAAACCA 1600 GCCGTGACAAATTTCGACATAACGAGGTACGATGTGGAACGAATCATGGCAAGCAGCACCCTCCTTGCTGGAGACCTGGCACGGCGAAACAAAGACATAGGACCTGCAAATGAGACTATCAACCACAATCTTTTAGTTCATAATAGCTACGgTGAAACCA 1600 GCCGTGACAAATTTCGACATAACGAGGTACGATGTGGAACGAATCATGGCAAGCAGCACCCTCCTTGCTGGAGACCTGGCACGGCGAAACAAAGACATAGGACCTGCAAATGAGACTATCAACCACAATCTTTTAGTTCATAATAGCTACGGTGAAACCA 1591

ACATATCACCAAAGAACAACGGGTCTCAACCAGACTGGAAAATCGTCCTTCACCAGTCCCCTGAACAGCAGATGGAGATGAAACAGGCAAATATGATTGAGAACTATAAGAGACAGGATTTCTCATTGGCCCCAGACAATCTGGTTGGGACGGACACAAT 1760 ACATATCACCAAAGAACAACGGGTCTCAACCAGACTGGAAAATCGTCCTTCACCAGTCCCCTGAACAGCAGATGGAGATGAAACAGGCAAATATGATTGAGAACTATAAGAGACAGGATTTCTCATTGGCCCCAGACAATCTGGTTGGGACGGACACAAT 1760

图 8 GH_A11G2251 在 182-9 和 W0 两个材料中的扩增序列比较

Fig. 8 Comparison of the amplified sequences of $G H \_A 11 G 2251$ in mutant $182-9$ and W0

\section{3 讨论}

棉纤维为棉花胚珠表皮突起形成，因此棉花的 主要经济性状一一棉纤维的品质和产量与棉花的生 殖生长密切相关。但是, 目前关于棉花中花器官形成
和发育的分子机制的研究报道并不多。本研究通过 转基因得到花器官突变体 182-9, 是研究花器官发 育的良好材料。本研究中, 我们鉴定出了准确的外 源 T-DNA 插入位点, 并在插入位点附近发现了 1 个 $A P 2$ 类基因家族基因。近年来, 关于 $A P 2$ 基因直接 
表 2 候选基因的注释信息

Table 2 Function annotation of the three candidate genes

\begin{tabular}{ccl}
\hline $\begin{array}{c}\text { 基因 ID } \\
\text { Gene ID }\end{array}$ & $\begin{array}{c}\text { 拟南芥中同源基因 } \\
\text { Homologous genes in Arabidopsis }\end{array}$ & \multicolumn{1}{c}{$\begin{array}{c}\text { 功能描述 } \\
\text { Function annotation }\end{array}$} \\
\hline$G H \_A 11 G 2251$ & $A N T$ & $A P 2$ 类乙烯反应转录因子 \\
& & $A P 2$-like ethylene-responsive transcription factor ANT \\
$G H \_A 11 G 2252$ & Atlg65750 & 假定核糖核酸酶 H 蛋白 At1g65750 \\
& & Putative ribonuclease H protein At1g65750 \\
GH_A11G2253 & $N A$ & NA \\
\hline
\end{tabular}

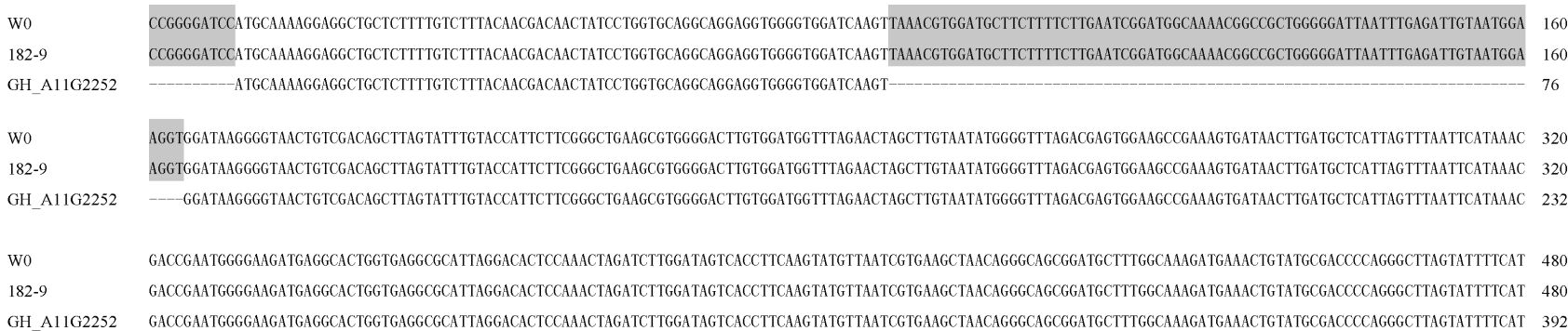

W0 TGATGTGCCGgACGTCATCGAGgAACAACTCATTGAGGATAGGCGTGGAATGCTGCCTATATCAGCAGAATTTATGCTCATGTGTAAGCTATCTAGAGTCCC 582 182-9 TGATGTGCCGGACGTCATCGAGGAACAACTCATTGAGGATAGGCGTGGAATGCTGCCTATATCAGCAGAATTTATGCTCATGTGTAAGCTATCTAGAGTCCC 582 GH A11G2252 TGATGTGCCGGACGTCATGGAGGAACAACTCATTGAGGATAGGCGTGGAATGCTGCCTATATCAGCAGAATTTATGCTCATGTGTAAGCTAT--AG---- 486

图 9 GH_A11G2252 在 182-9 和 W0 两个材料中的扩增序列比较

Fig. 9 Comparison of the amplified sequences of $G H \_A 11 G 2252$ in mutant 182-9 and W0

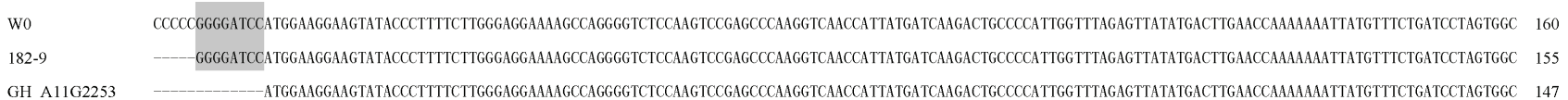

W0 TCGTCCAGCATTTTGGTTCATGAAAAGAAAGTTCCACCTCCTCCTCCATTATCTGTACAACTGAAGGGGAGCCCTTCCGGGAAAGGCGGCTTGAAGTGGTGGCAAGAGGACCCTTTTCTTCTGGCCTATAAAGCGTGTACCAAATCTGGGGGAAATATGA 320 182-9 TCGTCCAGCATTTTGGTTCATGAAAAGAAAGTTCCACCTCCTCCTCCATTATCTGTACAACTGAAGGGGAGCCCTTCCGGGAAAGGCGGCTTGAAGTGGTGGCAAGAGGACCCTTTTCTTCTGGCCTATAAAGCGTGTACCAAATCTGGGGGAAATATGA 315 GH_A11G2253 TCGTCCAGCATTTTGGTTCATGAAAAGAAAGTTCCACCTCCTCCTCCATTATCTGTACAACTGAAGGGGAGCCCTTCCGGGAAAGGCGGCTTGAAGTGGTGGCAAGAGGACCCTTTTCTTCTGGCCTATAAAGCGTGTACCAAATCTGGGGGAAATATGA 307

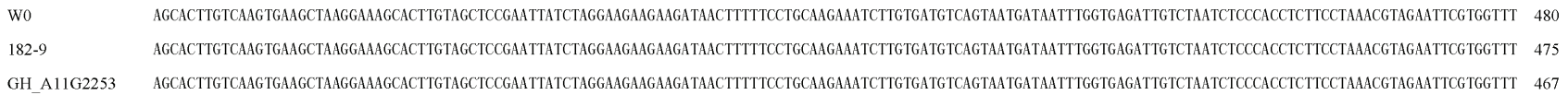

W0 ACATGAaTtTGTCTCTAGAgTCCC 504

182-9 ACATGAATTTGTCTCT---_- 491

GH_A11G2253 ACATGAATTTGTCTAG--_-_- 483

图 $10 G H A 11 G 2253$ 在 182-9 和 $\mathrm{W0}$ 两个材料中的扩增序列比较

Fig. 10 Comparison of the amplified sequences of $G H \_A 11 G 2253$ in mutant $182-9$ and W0

或间接参与花发育的某一具体调控仍存在许多问题， 对于其基因家族调节植物生长发育的方式及基因互 作也不是十分清楚 ${ }^{[21]}$ 。本研究中, 虽然 T-DNA 的插 入位置与 $G H \_A 11 G 2251$ 位置相差 $243 \mathrm{~kb}$, 但是在 DNA 的三维空间上, 他们可能是靠近的。这种现象 随着三维基因组研究 ${ }^{[26]}$ 的发展, 已经有更多的证据 证明了这种现象的存在。调控元件对基因的远程调 控也已有报道。比如, 在玉米中, 已有报道证明一个 控制光周期的 $Z m C C T 9$ 基因转录起始位点上游 57 $\mathrm{kb}$ 的 Harbinger 转座元件 CTOR 的插入调控了该基 因的表达 ${ }^{[27]}$ 。这种远程调控的作用机制为我们关于
候选基因与突变表型之间的可能关系提供了一些理论 依据。因此, 我们推测在突变体 182-9 中, T-DNA 的插 入可能引起了候选基因区域空间构象上的改变，从而 引起了基因的表达差异。突变体 182-9 花突变产生与 GH_A11G2251 的关系还需要更进一步的试验去证明。

\section{4 结论}

本研究通过花器官突变体 182-9 与其野生型 W0 的表型差异, 为阐明调控棉花花发育的基因及突变 机制提供了信息。鉴定出了 T-DNA 在转基因突变体 中的准确插入位点 A11:59,086,840, 并通过 PCR 以 

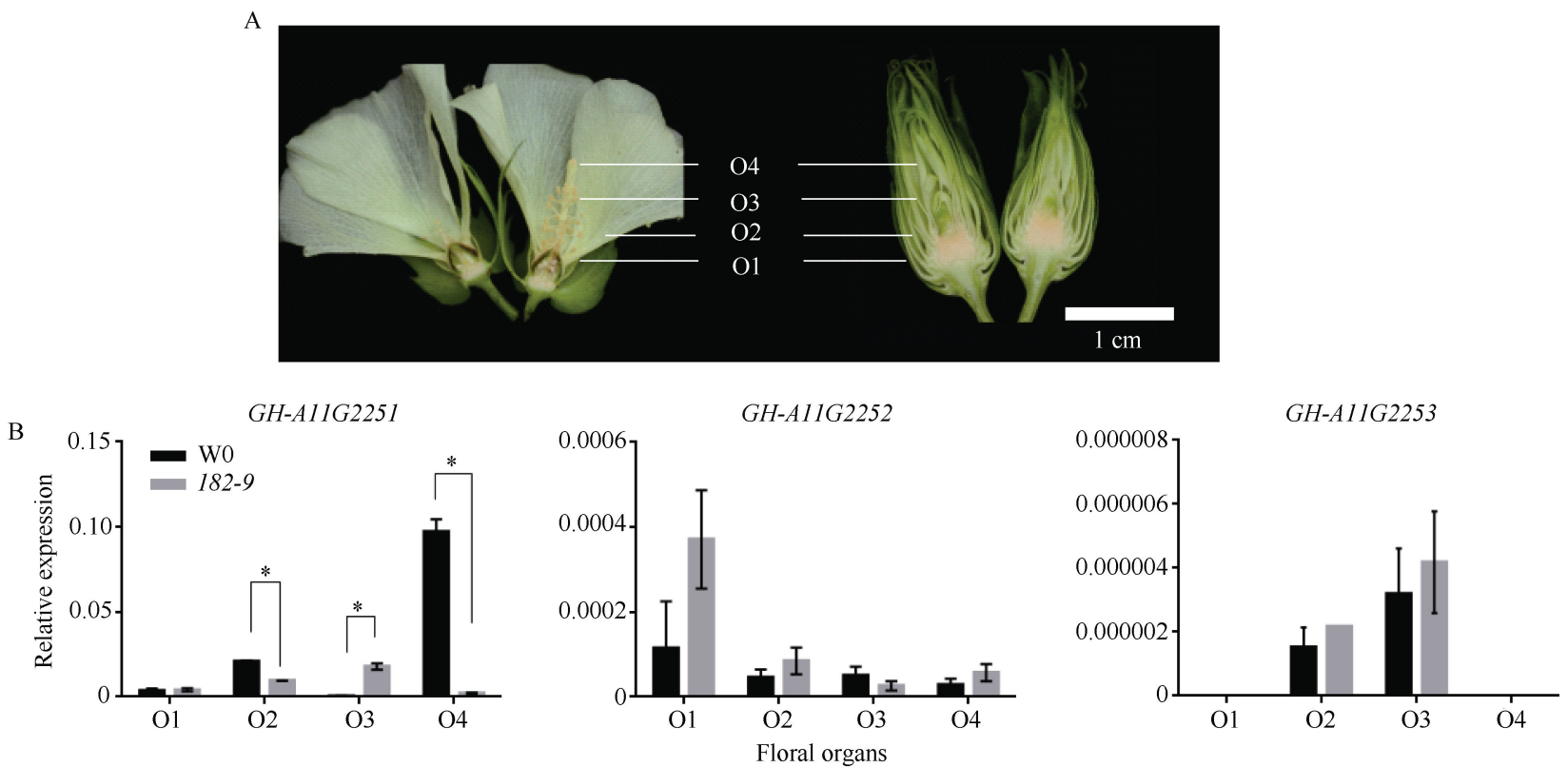

图 11 候选基因的在花器官中表达分析

Fig. 11 Relative expression levels of candidate genes in floral organs

A: W0 和 182-9 组织示意图; B: 候选基因在突变体 182-9 及其野生型 W0 中的表达水平。其中, *表示在 0.05 水平差异显著。

A: the schematic diagram of floral organs of W0 and 182-9; B: the expression levels of the candidate genes in mutant 182-9 and wild-type W0.

* means significant difference at the 0.05 probability level.

及 Southern 杂交进一步验证了位点鉴定的准确性。并 在插入位点附近发现了一个可能性的功能基因, 在 突变体 182-9 与转基因受体 $\mathrm{W} 0$ 的花器官中存在显 著差异表达。

\section{References}

[1] Zhang J, Guo W Z, Zhang T Z. Molecular linkage map of allotetraploid cotton (Gossypium hirsutum L. $\times$ Gossypium barbadense L.) with a haploid population. Theor Appl Genet, 2002, 105: 1166-1174.

[2] 陈良兵, 李永起. 棉花纤维发育的分子研究进展. 分子植物育 种, 2004, 2: 105-110.

Chen L B, Li Y Q. The research progress on cotton fiber development at molecular level. Mol Plant Breed, 2004, 2: 105-110 (in Chinese with English abstract).

[3] Silva C S, Puranik S, Round A, Brennich M, Jourdain A, Parcy F, Hugouvieux V, Zubieta C. Evolution of the plant reproduction master regulators LFY and the MADS transcription factors: the role of protein structure in the evolutionary development of the flower. Front Plant Sci, 2016, 6: 1193.

[4] Kotilainen M, Elomaa P, Uimari A, Albert V A, Yu D Y, Teeri T H. $G R C D 1$, an AGL2-like MADS box gene, participates in the C function during stamen development in Gerbera hybrida. Plant Cell, 2000, 12: 1893-1902.

[5] Theißen G. Development of floral organ identity: stories from the MADS house. Curr Opin Plant Biol, 2001, 4: 75-85.

[6] 张云, 刘青林. 植物花发育的分子机理研究进展. 植物学通报, 2003, 20: 589-601.

Zhang Y, Liu Q Y. Proceedings on molecular mechanism of plant flower development. Chin Bull Bot, 2003, 20: 589-601 (in Chinese with English abstract).

[7] Coen E S, Meyerowitz E M. The war of the whorls: genetic interactions controlling flower development. Nature, 1991, 353: 31-37.

[8] Kaufmann K, Melzer R, Theißen G. MIKC-type MADS-domain proteins: structural modularity, protein interactions and network evolution in land plants. Gene, 2005, 347: 183-198.

[9] 王亚杰. 巴西橡胶树 MADS-box 基因家族的克隆、表达谱分 析及功能验证. 海南大学硕士学位论文, 海南海口, 2017.

Wang Y J. Molcular Cloning, Expression Profile and Functional Analysis of MADS-box Genes in Hevea brasiliensis. MS Thesis of Hainan University, Haikou, Hainan, China, 2017 (in Chinese with English abstract).

[10] Jiao Y, Wickett N J, Ayyampalayam S, Chanderbali A S, Landherr L, Ralph P E, Tomsho L P, Hu Y, Liang H, Soltis P S. Ancestral polyploidy in seed plants and angiosperms. Nature, 2011, 473: 97-100.

[11] Ng M, Yanofsky M F. Function and evolution of the plant mads-box gene family. Nat Rev Genet, 2001, 2: 186-195.

[12] Elliott R C, Betzner A S, Huttner E, Oakes M P, Tucker W Q J, Gerentes D, Perez P, Smyth D R. AINTEGUMENTA, an APETALA2-like gene of Arabidopsis with pleiotropic roles in ovule development and floral organ growth. Plant Cell, 1996, 8: $155-168$.

[13] Klucher $\mathrm{K}$ M, Chow H, Reiser L, Fischer R L. The AINTEGUMENTA gene of Arabidopsis required for ovule and female gametophyte development is related to the floral homeotic gene APETALA2. Plant Cell, 1996, 8: 137-153.

[14] Schmid M, Uhlenhaut N H, Godard F, Demar M, Bressan R, Weigel D, Lohmann J U. Dissection of floral induction pathways 
using global expression analysis. Development, 2003, 130: 6001-6012.

[15] Aida M, Beis D, Heidstra R, Willemsen V, Blilou I, Galinha C, Nussaume L, Noh Y S, Amasino R, Scheres B. The PLETHORA genes mediate patterning of the Arabidopsis root stem cell niche. Cell, 2004, 119: 109-120.

[16] Zhao Q, Wang T, Wei X D. Function of $A P 2$ gene during floral organs development in higher plant: review. Chin J Trop Agric, 2005, 259: 50-56.

[17] Wang X Y, Fan S L, Song M Z, Pang C Y, Wei H L, Yu J W, Ma Q F, Yu S X, Fang D D. Upland cotton gene GhFPFl confers promotion of flowering time and shade-avoidance responses in Arabidopsis thaliana. PLoS One, 2014, 9: e91869.

[18] Zhang X H, Dou L L, Pang C Y, Song M Z, Yu S X. Genomic organization, differential expression, and functional analysis of the SPL gene family in Gossypium hirsutum. Mol Genet Genomics, 2015, 290: 115-126.

[19] Zhang X H, Wei J H, Fan S L, Song M Z, Pang C Y, Wei H L, Wang C S, Yu S Y. Functional characterization of GhSOCl and GhMADS42 homologs from upland cotton (Gossypium hirsutum L.). Plant Sci, 2016, 242: 178-186.

[20] 王力娜. 棉花 MADS-box 基因家族的克隆、表达谱分析及功 能验证. 中国农业科学院硕士学位论文, 北京, 2010.

Wang L N. Molecular Cloning, Expression Profile and Functional Analysis of MADS-Box Genes in Cotton. MS Thesis of Chinese Academy of Agricultural Sciences, Beijing, China, 2010 (in
Chinese with English abstract).

[21] 闻可心, 刘雪梅. $A P 2$ 功能基因在植物花发育中的重要作用. 生物技术通报, 2010, (2): 1-7.

Wen K X, Liu X M. The important role of $A P 2$ functional genes in plant floral developmen. Biotechnol Bull, 2010, (2): 1-7 (in Chinese with English abstract).

[22] Irish V F. Floral development in Arabidopsis. Plant Physiol Biochem, 1998, 36: 61-68.

[23] Bomblies K, Dagenais N, Weigel D. Redundant enhancers mediate transcriptional repression of AGAMOUS by APETALA2. Dev Biol, 1999, 216: 260-264.

[24] Altschul S F, Madden T L, Schffer A A, Zhang J H, Zhang Z, Miller W, Lipman D J. Gapped BLAST and PSI-BLAST: a new generation of protein database search programs. Nucleic Acids Res, 1997, 25: 3389-3402.

[25] Pertea M, Kim D, Pertea G M, Leek J T, Salzberg S L. Transcript-level expression analysis of RNA-seq experiments with HISAT, StringTie and Ballgown. Nat Protoc, 2016, 11: 1650.

[26] Lin D, Hong P, Zhang S H, Xu W Z, Jamal M, Yan K J, Lei Y Y, Li L, Ruan Y J, Fu Z F, Li G L, Cao G. Digestion-ligation-only $\mathrm{Hi}-\mathrm{C}$ is an efficient and cost-effective method for chromosome conformation capture. Nat Genet, 2018, 50: 754-763.

[27] Huang C, Sun H Y, Xu D Y, Chen Q Y, Tian F. ZmCCT9 enhances maize adaptation to higher latitudes. Proc Natl Acad Sci USA, 2018, 115: E334-E341. 